\title{
NSM SHEAR STRENGTHENING TECHNIQUE WITH CFRP LAMINATES APPLIED IN HIGH- STRENGTH CONCRETE BEAMS WITH OR WITHOUT PRE-CRACKING
}

\author{
S. J. E. Dias ${ }^{1}$ and J. A. O. Barros ${ }^{2}$ \\ ${ }^{1}$ Auxiliary Prof., ISISE, Dep. of Civil Eng., Univ. of Minho, Azurém, 4810-058 Guimarães, Portugal \\ 2 Associate Prof., ISISE, Dep. of Civil Eng., Univ. of Minho, Azurém, 4810-058 Guimarães, Portugal
}

\begin{abstract}
The effectiveness of the near surface mounted (NSM) shear strengthening technique with carbon fiber reinforced polymer (CFRP) laminates applied in high-strength concrete beams with a certain percentage of existing steel stirrups is assessed by experimental research. In this context, the influence of the following main parameters are investigated: (i) the percentage and the inclination of the CFRP laminates; (ii) the percentage of existing steel stirrups; (iii) the existence of cracks when the reinforced concrete (RC) beams are shear strengthened with NSM CFRP laminates. The results showed that the NSM shear strengthening technique with CFRP laminates is more effective when applied to RC beams of high-strength concrete, not only in terms of increasing the load carrying capacity of the beams, but also in assuring higher mobilization of the tensile properties of the CFRP. Inclined laminates were more effective than vertical laminates, and the shear resistance of the beams has increased with the percentage of laminates. Pre-cracked RC beams strengthened with NSM CFRP laminates have presented a load carrying capacity similar to that of the homologous uncracked strengthened beams.
\end{abstract}

KEYWORDS: A. Carbon fiber; A. Laminates; B. Strength; D. Mechanical testing; Near Surface Mounted (NSM) technique

\section{INTRODUCTION}

A significant number of reinforced concrete (RC) structural elements of buildings and bridges, in all over the world, needs rehabilitation and strengthening, which indicates that the relevance of these activities in the civil construction industry is expected to continue of increasing in the next decades. Using advanced composites materials like carbon fiber reinforced polymers (CFRP), competitive structural strengthening solutions can be developed due to the high strength-to-weight ratio, high durability (non corrodible), electromagnetic neutrality, ease

\footnotetext{
${ }^{1}$ Author to whom the correspondence should be sent (sdias@civil.uminho.pt).
} 
of handling, rapid execution with low labor, and practically unlimited availability in size, geometry and dimension of these materials [1-3]. For the strengthening of structural components of bridges, the possibility of making relative fast interventions without interfering with their normal functionality are important advantages of the CFRP-based strengthening solutions.

A RC beam needs to be shear strengthened when is deficiently reinforced in shear, becomes subjected to higher loads, or when its shear capacity falls below its flexural capacity after flexural strengthening. The shear failure mode of a RC element should be avoided since it is brittle and unpredictable. Externally bonded reinforcement (EBR) and near surface mounted (NSM) with CFRP are techniques that can be used for the shear strengthening of RC beams. In the EBR technique wet lay-up CFRP sheets (discrete or continuous) can be applied in distinct arrangements: full wrapping the beam cross section [4]; bonding three sides of the beam cross section, in a U-wrap shape [5]; bonding the two lateral beam surfaces [5]. The use of precured CFRP laminates, bonded to the lateral beam surfaces by epoxy adhesive [6], is also another shear strengthening configuration in the EBR technique. Furthermore, a L configuration CFRP laminate with high rugosity of the faces bonded to concrete was also proposed to enhance the strengthening efficacy of EBR systems [7]. In general, all of the above mentioned EBR systems provide an increase of the shear resistance of $\mathrm{RC}$ beams, however, premature debond can question the profitability of some of these strengthening configurations.

The NSM is an alternative to the EBR technique, based on fixing, by epoxy adhesive, CFRP bars of circular [8] or rectangular [9-10] cross section shape, into slits opened on the concrete cover of the lateral beam surfaces. Due to the larger bond area and higher confinement provided by the surrounding concrete, narrow strips of CFRP laminates of rectangular cross section, installed into thin slits and bonded to concrete by an epoxy adhesive, are the most effective CFRP strengthening elements for the NSM technique [11-12]. Dias and Barros demonstrated by experimental research that NSM technique provides higher effectiveness than EBR technique for the shear strengthening of rectangular cross sectional RC beams without steel stirrups [13], and T cross sectional RC beams having a certain percentage of existing steel stirrups [14]. In fact, NSM was the most effective, not only in terms of increasing the beam shear resistance, but also in using more effectively the relatively high tensile strength of the CFRP material. This is a consequence of the larger CFRP laminate-concrete bond stress values that can be mobilized in the NSM technique (both faces of the CFRP are bonded to concrete). A further advantage of the NSM technique is its ability to significantly reduce the probability of harm resulting from acts of vandalism, mechanical damages and aging effects. Furthermore, when NSM is used, the appearance of a structural element is practically unaffected by the strengthening intervention. 
Previous experimental work [15] showed that the concrete quality has an important role on the effectiveness of the NSM shear strengthening technique with CFRP laminates. Namely, the lower is the concrete strength class the lesser is the effectiveness of the NSM technique. This fact indicates that NSM can have a high performance for the case of RC structures with relatively high-strength concrete. To appraise the performance of the application of NSM CFRP laminates for the shear strengthening of $\mathrm{T}$ cross sectional reinforced high strength concrete beams having a certain percentage of existing steel stirrups, an experimental program was carried out. Six NSM shear strengthening configurations (three CFRP orientations and two levels of CFRP percentage) were applied in T cross section RC beams with a steel stirrups percentage of $0.10 \%\left(\rho_{s w}=0.10 \%\right)$. Four of these NSM configurations were also applied in beams with $\rho_{s w}$ of $0.16 \%$. The strengthening intervention often involves concrete elements already cracked. To evaluate the influence, on the strengthening effectiveness, of already existing cracks when a beam is shear strengthened with NSM CFRP laminates, some of the RC beams were pre-cracked prior to their strengthening. A detailed description of the carried out experimental, research and a discussion of the obtained results are done in the present paper.

\section{EXPERIMENTAL PROGRAM}

\subsection{Test series}

Fig. 1 presents the $\mathrm{T}$ cross section of the beams adopted in the experimental program, the lateral geometry of the type of beam and the steel reinforcement common to all tested beams (seventeen). The reinforcement systems were designed in order that all beams fail in shear. To avoid shear failure in the $\mathrm{L}_{\mathrm{r}}$ beam span, steel stirrups of $8 \mathrm{~mm}$ diameter spaced at $80 \mathrm{~mm}(\phi 8 @ 80 \mathrm{~mm})$ were applied in this span, as shown in Fig. 1. The differences between the tested beams are restricted to the shear reinforcement systems applied in the $\mathrm{L}_{\mathrm{i}}$ beam span (the shear span $\mathrm{L}_{\mathrm{i}}$ is 3.3 times the effective depth of the beam, $\mathrm{L}_{\mathrm{i}} / \mathrm{d}=3.3$ ).

The experimental program is composed of three reference beams and two groups of NSM shear-strengthened beams. The reference beams (Fig. 2) consists of: one beam without any shear reinforcement (C-R beam); one beam with steel stirrups $\phi 6 @ 300 \mathrm{~mm}$ (3S-R beam, with a percentage of stirrups, $\rho_{s w}$, of $\left.0.10 \%\right)$; one beam with steel stirrups $\phi 6 @ 200 \mathrm{~mm}\left(5 \mathrm{~S}-\mathrm{R}\right.$ beam, with $\left.\rho_{s w}=0.16 \%\right)$.

For the NSM shear-strengthened beams, the first group is composed by eight beams (3S-6LV, 3S-10LV, 3S5LI45, 3S-5LI45F1, 3S-5LI45F2, 3S-9LI45, 3S-5LI60 and 3S-8LI60) with the percentage of stirrups adopted in the 3S-R reference beam $\left(\rho_{s w}=0.10 \%\right)$ and having the CFRP shear strengthening arrangements indicated in Table 1 
and Fig. 3. Three distinct orientations of the CFRP $\left(45^{\circ}, 60^{\circ}\right.$ and $\left.90^{\circ}\right)$ were considered and, for each CFRP orientation, two percentages of laminates were analyzed. The second group of NSM shear strengthened beams (see Table 1 and Fig. 3) is comprised by six beams (5S-5LI45, 5S-5LI45F, 5S-9LI45, 5S-5LI60, 5S-5LI60F and 5S8LI60) that have the percentage of stirrups used in the 5S-R reference beam $\left(\rho_{s w}=0.16 \%\right)$, and the adopted NSM strengthening configurations were those corresponding to the inclined laminates $\left(45^{\circ}\right.$ and $\left.60^{\circ}\right)$ applied in the first group of beams. The two groups of beams with CFRP laminates were prepared to be also investigated the influence of the amount of existing steel stirrups on the effectiveness of the NSM shear strengthening technique. The 3S5LI45F1, 3S-5LI45F2, 5S-5LI45F and 5S-5LI60F beams were pre-cracked before have been strengthened.

For the both two groups of NSM beams the lower percentage of laminates was designed in order to present similar maximum load, regardless the orientation of the laminates [14]. The same strategy was adopted on the design of the beams strengthened with the higher percentage of laminates. In this design it was assumed that a CFRP laminate works like a steel stirrup. However, instead of considering the yield stress of the material, a stress in the laminates corresponding to a strain of $0.5 \%$ was adopted, since this is a compromise between the maximum value recommended by ACI [1] for the EBR (0.4\%), and the $0.59 \%$ value obtained in pullout bending tests with NSM strengthening technique using CFRP laminates [16]. As schematically represented in Fig. 1, the laminates were distributed along the AB line, where A represents the beam's support at its "test side" and B is obtained assuming load degradation at $45^{\circ}$.

The experimental program is composed of two types of three-point beam bending tests. In the test type I four RC beams were loaded in order to develop a specific level of cracking in the concrete (pre-cracks) prior the application of the CFRP. In the test type II all RC beams were loaded up to failure. The three point beam bending tests (Fig. 1) were carried out using a servo closed-loop control equipment, taking the signal read in the displacement transducer (LVDT), placed at the loaded section, to control the test at a deflection rate of $0.01 \mathrm{~mm} / \mathrm{second}$. To prevent brittle spalling of the concrete cover at the supports, the beam ends were strengthened by confining the concrete with a two-directional cage of $\phi 6 @ 65 \mathrm{~mm}$ horizontal stirrups and $\phi 10 @ 50 \mathrm{~mm}$ vertical stirrups (Figs. 1 and 2). To overcome the difficulties of bending the $\$ 32 \mathrm{~mm}$ longitudinal tensile bars, their ends were welded to the steel plates.

With the purpose of obtaining the strain variation along the three laminates (CFRP A, CFRP B and CFRP C: see the 3S-6LV beam in Fig. 3) that have the highest probability of providing the largest contribution for the shear strengthening of the RC beam, four strain gauges (SG_L) were bonded in CFRP B and three SG_L were bonded in CFRP A and C according to the arrangements represented in Fig. 4. These SG_L arrangements were adopted for the beams without pre-cracks (in the following section it will be presented the adopted SG_L arrangements in the pre- 
cracked NSM beams). One steel stirrup was monitored with three strain gauges (SG_S) installed according to the configuration represented in Fig. 4. The location of the monitored laminates and stirrups in the NSM strengthened beams is represented in Fig. 3.

\subsection{Material properties}

The concrete compressive strength was evaluated at the age of the beams tests, carrying out direct compression tests with cylinders of $150 \mathrm{~mm}$ diameter and $300 \mathrm{~mm}$ height, according to EN 206-1 [17]. In the tested beams, high bond steel bars of $6,8,12,16$ (two types) and $32 \mathrm{~mm}$ diameter were used. The values of their main tensile properties were obtained from uniaxial tensile tests performed according to the recommendations of EN 10002-1 [18]. The tensile properties of the CFK 150/2000 S\&P laminates were characterized by uniaxial tensile tests carried out according to ISO 527-5 [19]. Table 2 includes the average values obtained from these experimental programs. The MBrace Resin 220 [20] epoxy adhesive was used to bond the laminates to the concrete. This type of adhesive was tested by Bonaldo et al. [21] and the average values obtained in terms of ultimate tensile stress, ultimate tensile strain and modulus of elasticity were $33 \mathrm{MPa}, 4.83 \%$ and $7.47 \mathrm{GPa}$, respectively.

\subsection{Strengthening technique}

To apply the precured CFRP laminates using NSM technique, the following procedures were executed: 1) using a diamond cutter, slits of about 4-5 mm width and 12-15 $\mathrm{mm}$ depth were opened on the concrete cover (of about $22 \mathrm{~mm}$ thickness) of the lateral faces of the beam web, according to the pre-defined arrangement for the laminates (the laminates were not anchored to the beam flange; they were restricted to the beam web); 2) the slits were cleaned by compressed air; 3) the laminates, supplied in rolls of $150 \mathrm{~m}$, and having a cross-section of $1.4 \times 9.5 \mathrm{~mm}^{2}$, were cut with the desired length and cleaned with acetone; 4) the epoxy adhesive was produced according to the supplier recommendations; 5) the slits were filled with the adhesive; 6) a layer of adhesive was applied on the faces of the laminates; and 7) the laminates were inserted into the slits and adhesive in excess was removed.

To guarantee a proper curing of the adhesive, at least one week was taken between the beam strengthening operations and the beam test. 


\section{RESULTS}

\subsection{Pre-cracking test (Type I)}

As already mentioned, prior to the application of the CFRP strengthening systems, four RC beams (3S-5LI45F1, 3S-5LI45F2, 5S-5LI45F and 5S-5LI60F) were loaded up to a shear crack pattern was formed. For this purpose, and taking into account the behavior of the 3S-R and 5S-R reference beams (these beams were previously tested up to failure), a test stop criterion of a deflection of $3 \mathrm{~mm}$ at the loaded section was adopted. This value is about $30 \%$ of the deflection corresponding to $l / 250$, which is the maximum allowed deflection for serviceability limit states according to the Eurocode [23], where $l$ is the beam span length.

The relationship between the force and the deflection at the loaded-section $\left(\mathrm{F}-u_{L S}\right)$ in the above mentioned four beams is represented in Fig. 5. The maximum load in the pre-cracking test was 239.9 kN, 232.6 kN, 245.4 kN and $253.4 \mathrm{kN}$ for the $3 \mathrm{~S}-5 \mathrm{LI} 45 \mathrm{~F} 1,3 \mathrm{~S}-5 \mathrm{LI} 45 \mathrm{~F} 2,5 \mathrm{~S}-5 \mathrm{LI} 45 \mathrm{~F}$ and $5 \mathrm{~S}-5 \mathrm{LI} 60 \mathrm{~F}$ beams, respectively. The applied load was then removed and, due to practical reasons, the strengthening activities were executed with the beams in the unloaded state (Fig. 6). The differences between 3S-5LI45F1 and 3S-5LI45F2 beams are restricted to the number of laminates crossing the shear crack formed during the test type I (pre-cracking) - see in Fig. 6 the cracking pattern of the beams after test type I. After the adhesive has been cured, the beams were tested up to failure (test type II). The localization of the strain gauges (Table 3) was governed by the crack pattern formed at the end of the pre-cracking test. Therefore, in order to obtain the maximum strain values, strain gauges were positioned in the interceptions with the shear cracks.

\subsection{Test up to failure (Type II)}

\subsubsection{Load carrying capacity of the tested beams without pre-cracks}

The relationship between the applied force and the deflection at the loaded section $\left(u_{L S}\right)$ for the tested beams without pre-cracks is represented in Figs. $7 \mathrm{a}$ and $7 \mathrm{~b}$ for the lower percentage of steel stirrups, and Figs. $8 \mathrm{a}$ and $8 \mathrm{~b}$ for higher percentage of steel stirrups. As Fig. $8 \mathrm{~b}$ shows, $\Delta F$ represents the increase of the load provided by a shear strengthening system, while $F^{\text {ref }}$ is the corresponding load capacity of the reference beam. For deflections greater than the corresponding to the formation of the first shear crack in the reference beam, the $\Delta F / F^{\text {ref }}$ ratio was evaluated, and the $\Delta F / F^{r e f}$ vs $u_{L S}$ relationship is depicted in Figs. $7 \mathrm{c}$ and $7 \mathrm{~d}$ for the series where $3 \mathrm{~S}-\mathrm{R}$ is the reference beam, and in Figs. $8 \mathrm{c}$ and $8 \mathrm{~d}$ for the series where $5 \mathrm{~S}-\mathrm{R}$ is the reference beam. Assuming that

$\Delta F_{\max }=F_{\max }-F_{\max }^{r e f}$, being $F_{\max }^{r e f}$ and $F_{\max }$ the load carrying capacity (maximum force) of the reference beam (3S-R 
or 5S-R) and of the shear strengthened beam, respectively, the $\Delta F_{\max } / F_{\max }^{\text {ref }}$ ratio was evaluated. The values for $F_{\max }, \Delta F_{\max } / F_{\max }^{r e f}$, and the deflection at loaded section corresponding to $F_{\max }\left(u_{F_{\max }}\right)$ are included in Table 4. Apart 3S-6LV beam, where $\left(\Delta F / F^{\text {ref }}\right)_{\max }$ occurred for a $u_{L S}=5.72 \mathrm{~mm}(=7.8 \%)$, the $\left(\Delta F / F^{\text {ref }}\right)_{\max }$ values were equal to the $\Delta F_{\max } / F_{\max }^{\text {ref }}$ values.

Fig. 7 and Fig. 8, and the results included in Table 4 show that, for deflections higher than the one corresponding to the formation of the first shear crack in the reference beams $\left(u_{L S}=2.96 \mathrm{~mm}\right.$ for $3 \mathrm{~S}-\mathrm{R}$ beam (Fig. 7$)$ and $u_{L S}=$ $3.9 \mathrm{~mm}$ for 5S-R beam (Fig. 8)), the adopted CFRP configurations provided an increase in the beam load carrying capacity. This reveals that the CFRP laminates bridging the surfaces of the shear crack offer resistance, mainly to crack opening, resulting a smaller degradation of the shear stress transfer between the faces of the crack due to aggregate interlock effect. Therefore, for deflections above the deflection corresponding to the formation of the shear crack in the reference beams, an increase of the beam stiffness is observed in the shear strengthened beams. The crack opening resisting mechanisms provided by the crack bridging laminates also contribute to increase the load at which stirrups enter in their plastic phase.

Fig. 7 and Fig. 8 show that the typical diagram of the behavior of a NSM shear strengthened beam is characterized by a first branch up to the formation of the shear crack that almost coincides with the one of the reference beam, followed by a branch revealing that the load carrying capacity of the strengthened beam is higher than the reference beam.

The CFRP shear strengthening configurations provided an increase in terms of stiffness (after shear crack formation) and in terms of maximum load $\left(F_{\max }\right)$. Furthermore, apart the 3S-6LV beam, the values of the deflection at the loaded section $\left(u_{L S}\right)$ in correspondence to $F_{\max }$ of the strengthened beams were higher than those occurred in the reference beams.

The strengthening arrangements corresponding to the lower percentage of CFRP had the following increments in terms of beam load carrying capacity $\left(\Delta F_{\max } / F_{\max }^{r e f}\right): 7.5 \%, 36.7 \%$ and $38.3 \%$ for the beams strengthened with laminates at $90^{\circ}$ (3S-6LV beam), $45^{\circ}$ (3S-5LI45 beam) and $60^{\circ}$ (3S-5LI60 beam), respectively, and with $\rho_{s w}=$ $0.10 \%$ (three steel stirrups in the $\mathrm{L}_{\mathrm{i}}$ beam shear span); $36.6 \%$ and $35.8 \%$ for the beams strengthened with laminates at $45^{\circ}$ (5S-5LI45 beam) and laminates at $60^{\circ}$ (5S-5LI60 beam), respectively, and with $\rho_{s w}=0.16 \%$ (five steel stirrups in the $\mathrm{L}_{\mathrm{i}}$ beam shear span). Regardless the percentage of steel stirrups considered, the configurations with laminates at $45^{\circ}$ and $60^{\circ}$ had similar performance. 
The strengthening arrangements corresponding to the higher percentage of CFRP had the following increments in terms of beam load carrying capacity $\left(\Delta F_{\max } / F_{\max }^{r e f}\right): 36.6 \%, 56.6 \%$ and $62.4 \%$ for the beams strengthened with laminates at $90^{\circ}(3 \mathrm{~S}-10 \mathrm{LV}), 45^{\circ}\left(3 \mathrm{~S}-9 \mathrm{LI} 45\right.$ beam) and $60^{\circ}(3 \mathrm{~S}-8 \mathrm{LI} 60$ beam $)$, respectively, and with $\rho_{s w}=0.10 \%$; $53.2 \%$ and $59.8 \%$ for the beams strengthened with laminates at $45^{\circ}\left(5 \mathrm{~S}-9 \mathrm{LI} 45\right.$ beam) and laminates at $60^{\circ}(5 \mathrm{~S}-8 \mathrm{LI} 60$ beam), respectively, and with $\rho_{s w}=0.16 \%$. For these series, laminates at $60^{\circ}$ were more effective than laminates at $45^{\circ}$ (about $\left.11 \%\right)$

The results showed that regardless the CFRP percentage, inclined laminates were more effective than vertical laminates (see Table 4). This is justified by the orientation of the shear failure cracks that had a tendency to be almost orthogonal to inclined laminates. Furthermore, for vertical laminates the total resisting bond length of the CFRP is lower than that of inclined laminates. After the formation of a shear crack in the reference beam, the $\left(\Delta F / F^{r e f}\right)_{\max }$ and $\Delta F_{\max } / F_{\max }^{r e f}$ values of the strengthened beams with the larger percentage of CFRP $\left(\rho_{f w}\right)$ were higher than the corresponding values of the beams strengthened with the lower $\rho_{f w}$. The effectiveness of the CFRP was higher in the beams with the lower percentage of steel stirrups analyzed. According to the experimental results, for an increase from $0.10 \%$ to $0.16 \%$ in the percentage of steel stirrups in the $\mathrm{L}_{\mathrm{i}}$ beam span, the NSM strengthening effectiveness has an average decrease of $4 \%$ (see Fig. 9), which is much smaller than the decrease registered in RC beams of lower strength class [15].

\subsubsection{Failure modes of the beams without pre-cracks}

As expected, all tested beams failed in shear. Fig. 10 includes details of the shear failure zones of the tested beams without pre-cracks (the steel stirrups at the $\mathrm{L}_{\mathrm{i}}$ beam shear span are indicated by vertical lines, and the circles indicate the zone where stirrups have ruptured, see also Fig. 2 and Fig. 3).

In $\mathrm{C}-\mathrm{R}$ beam, the shear crack has widened intensively when the maximum load was attained. For the $3 \mathrm{~S}-\mathrm{R}$ and 5S-R beams, the maximum load was attained when one stirrup that crossed the shear failure crack has ruptured.

Two types of failure modes have essentially occurred in the beams with the lowest percentage of CFRP. The first, which occurred in the 3S-6LV, 3S-5LI45, 5S-5LI45 and 5S-5LI60 beams, consisted in the sliding of the CFRP (interface between the CFRP and the adhesive) crossed by the shear failure crack (Fig. 11b). The failure of the 3S5LI60 beam occurred with the rupture of the intermediate laminate (Fig. 11a). In general, these failure modes were different from those observed in the NSM shear strengthening beams tested in previous experimental programs [1415], where, at failure, a certain concrete volume was attached to the laminates. The higher concrete strength class of 
the beams of the present experimental program can justify these distinct types of failures modes, since concrete was not so prone to fracture during the debond process of the laminates bridging the shear failure crack.

Debond through the laminate-adhesive interface (laminate sliding) was the predominant failure mode of the beams with the highest percentage of CFRP. In beams where the laminates were crossed by the critical shear crack, in such a way that the bond transference length of these laminates was relatively small, the failure occurred due to the concrete fracture, having the concrete become adhered to the laminates along this length (Fig. 11c). In the 5S9LI45 beam, due to the relatively small spacing between laminates, the group effect [22] has conducted to the detachment of the concrete cover (Fig. 11c).

\subsubsection{Strains in the CFRP and steel stirrups in the beams without pre-cracks}

The maximum strain recorded in the monitored laminates up to the maximum load of the beams $\left(\varepsilon_{C F R P}^{\max }-\right.$ see Table 4) has ranged from $0.82 \%$ (3S-6LV beam) and 1.5\% (3S-5LI60 beam). In terms of the average value of the maximum strains registered in the monitored laminates (three per beam) $\left(\left(\varepsilon_{C F R P}^{\max }\right)_{\text {med }}\right.$ - see Table 4$)$, the variation was between $0.39 \%$ in the 3S-6LV beam and $0.99 \%$ in the 5S-5LI45 beam. For all tested strengthened beams without pre-cracks the average value of $\varepsilon_{C F R P}^{\max }$ and $\left(\varepsilon_{C F R P}^{\max }\right)_{m e d}$ was $1.07 \%$ and $0.80 \%$, respectively. In terms of CFRP orientation, the average value of the maximum strain $\left(\varepsilon_{C F R P}^{\max }\right)$ was $1.09 \%, 1.17 \%$ and $0.84 \%$ for the beams with laminates at $45^{\circ}, 60^{\circ}$ and $90^{\circ}$, respectively. These values range from $51 \%$ to $72 \%$ of the CFRP ultimate rupture $\operatorname{strain}\left(\varepsilon_{f u}=1.63 \%\right.$ - see Table 2$)$.

Fig. 12 illustrates a representative variation of the strains on the monitored laminates and stirrups during the beam loading process up to the maximum load (3S-5LI60 beam). It is observed that the curves feature two phases. In the initial stage of loading, while the CFRP was not crossed by a diagonal crack, the contribution of the laminate for the beam load-carrying capacity is marginal. The second stage initiates when the CFRP was crossed by a diagonal crack. This behaviour was similar in all monitored stirrup. Fig. 12 shows that the maximum strain value in the laminates was registered in the SG_L2 (1.5\% - see Table 4) of the CFRP B, since it was the closest to the shear failure crack. SG_L1 and SG_L3 of the CFRP B had a similar variation, since they were almost symmetrically positioned in relation to the plane of the shear failure crack. SG_L4 of the CFRP B recorded the lowest strain values in this laminate, since it was at the furthest distance from the shear failure crack. The gradient of strains registered in the SG was the higher the closer was the SG from the crack plane. This tendency was also observed in the CFRP A, CFRP C and steel stirrup. Therefore, at about $205 \mathrm{kN}$ the critical diagonal crack was formed, activating the 
laminates and the stirrup it has crossed (see SG_L2 in the CFRP B, SG_L3 in the CFRP C and SG_S1 in the stirrup). At about $300 \mathrm{kN}$ a new crack has crossed the CFRP A near the SG_L2, leading to an abrupt gradient of strains in this SG. At around $400 \mathrm{kN}$ the opening process of the critical diagonal shear crack has accentuated, causing a considerable increase in some strain gauges, up to the failure load of the beam. The yield strain of the monitored stirrup was attained for a load of about $295 \mathrm{kN}$, which is well below the load carrying capacity of the beam, which means that the tensile capacity of the stirrup was entirely mobilized.

\subsubsection{Effect of the pre-cracks}

Fig. 13 shows the relationship between the applied load and the deflection at the loaded section $\left(u_{L S}\right)$ for the NSM beams where the difference between them is restricted to the presence, or not, of pre-cracks when the strengthening intervention is applied (3S-5LI45F1 and 3S-5LI45F2 beams in Fig. 13a, and 5S-5LI45F and 5S5LI60F beams in Fig. 13b were pre-cracked: ). For these beams Table 6 shows the maximum force $\left(F_{\max }\right)$, the deflection at the loaded section when $F_{\max }$ was registered $\left(u_{F_{\max }}\right)$, and the values of $\Delta F_{\max } / F_{\max }^{r e f}$. Fig. 14 includes details of the shear failure zones of the pre-cracked NSM strengthened beams.

The main difference between the behavior of strengthened beams with or without pre-cracks resides in an expected loss of initial stiffness in the pre-cracked specimens (up to the maximum load applied in the pre-cracking test). This difference was more evident in the beams with $\rho_{s w}=0.10 \%$. Above the load corresponding to the end of the pre-cracking test, the structural performance of 3S-5LI45F1 and 5S-5LI45F beams was slightly higher than the respective beams without a pre-cracking test (3S-5LI45 and 5S-5LI45, respectively). The maximum load ( $\left.F_{\max }\right)$ of 3S-5LI45F2 and 5S-5LI60F beams had similar values to the respective uncracked strengthened beams (3S-5LI45 and 5S-5LI60, respectively). The obtained results showed that the efficacy of the NSM shear strengthening technique with CFRP laminates is not negatively affected by the presence of a crack pattern that may exists for the load levels corresponding to the serviceability limit states.

Table 5 also compares the values of $\varepsilon_{C F R P}^{\max }$ and $\left(\varepsilon_{C F R P}^{\max }\right)_{m e d}$ registered in the NSM beams with pre-cracks and in homologous beams without pre-cracks. The maximum strain recorded in the monitored laminates up to the maximum load $\left(\varepsilon_{C F R P}^{\max }\right)$ in the pre-cracked beams has ranged between $1.21 \%(5 \mathrm{~S}-5 \mathrm{LI} 45 \mathrm{~F}$ beam) and $1.49 \%$ (3S5LI45F1 beam). These values correspond to $74 \%$ and $91 \%$ of the CFRP ultimate strain $\left(\varepsilon_{f u}=1.63 \%-\right.$ see Table 2$)$. In terms of $\left(\varepsilon_{C F R P}^{\max }\right)_{m e d}$, the variation was between $1.03 \%$ in the 5S-5LI45F beam, and $1.20 \%$ in the 3S-5LI45F1 
beam. For all pre-cracked shear strengthened beams the average value of $\varepsilon_{C F R P}^{\max }$ and $\left(\varepsilon_{C F R P}^{\max }\right)_{\operatorname{med}}$ was $1.38 \%$ and $1.09 \%$, respectively.

Fig. 15 represents the variation of the strains on the monitored laminates, during the loading process up to the maximum load of the 5S-5LI60F beam. Since strain gauges were installed in the sections of the laminates crossed by shear cracks, these strain gauges have registered a significant increase of strains just from the beginning of the loading process (SG_L2 in CFRP A, SG_L2 in CFRP B and SG_L1 in CFRP C, Fig. 15). In the non pre-cracked beams, a significant increase of strains in the laminates only occurred just after the formation of the shear crack.

\section{CONCLUSIONS}

In the present paper the effectiveness of the NSM shear strengthening technique with CFRP laminates applied in high-strength concrete beams reinforced with a certain percentage of existing steel stirrups, and with or without precracks, was assessed by experimental research. Distinct CFRP shear strengthening arrangements were used and their performance was appraised in terms of load carrying capacity, stiffness of the response of the beams after the formation of the shear failure crack in the reference beam, maximum strains measured in the CFRP, and failure modes. The influence of the percentage and inclination of the laminates and the percentage of existing steel stirrups was also evaluated.

From the obtained results it can be concluded that the NSM shear strengthening technique with CFRP laminates is highly effective in RC beams of an average concrete compressive strength of about $60 \mathrm{MPa}$. Taking also into account results in previous experimental programs, it can be concluded that the NSM shear strengthening effectiveness with CFRP laminates increases with the concrete strength class. The adopted NSM shear strengthening configurations, mainly those with laminates at 45 and 60 degrees, have significantly enhanced the overall behavior of the RC beams, since they provided a significant increase in terms of ultimate load and ultimate deflection. The increase in terms of load carrying capacity provided by the CFRP shear strengthening configurations is only significant above the deflection corresponding to the formation of the shear crack in the corresponding unstrengthened reference beam. Apart 3S-6LV beam, the CFRP shear strengthening configurations provided an increase in terms of maximum load that ranged between $35 \%$ and $62 \%$ of the maximum load of the reference beams.

Regardless the percentage of CFRP, the inclined laminates were more effective than vertical laminates, and the beam load carrying capacity has increased with the percentage of CFRP. When compared with previous results obtained in beams of lower concrete strength class, the detrimental effect of the NSM shear strengthening effectiveness resulting from the increase of the percentage of existing steel stirrups was much smaller. Debond 
through the laminate-adhesive interface (laminate sliding) was the predominant failure mode of the tested beams. In the beams where the laminates crossed by the critical shear crack had a relatively small bond transference length, the failure occurred due to concrete fracture, with the concrete adhered to the laminates. In 3S-5LI60 beam the laminate crossed by the shear failure crack was ruptured.

Due to the relatively high-strength concrete used, the resistance to the concrete fracture propagation during the debond process of the laminates crossing the critical diagonal crack has mobilized significantly the tensile capacity of the CFRP laminates. In fact, the maximum strain recorded in the laminates up to the maximum load has ranged between $0.82 \%$ and $1.5 \%$. These values correspond to $50 \%$ and $92 \%$ of the CFRP ultimate strain (1.63\%), respectively. The highest values of the maximum strain were recorded in the beams with the lower percentage of inclined laminates. Beams with pre-cracks had higher values of the maximum strain than homologous beams without pre-cracks.

The main difference of the behavior of NSM CFRP beams with and without pre-cracks resides in an expected loss of initial stiffness in the pre-cracked beams. In these beams the mobilization of the CFRP laminates started just after the opening process of the pre-cracks, while the mobilization of the CFRP laminates in the non pre-cracked beams only occurred when the shear crack has formed. However, the pre-cracking did not affect the efficacy of the NSM shear strengthening technique in terms of load carrying capacity and ultimate deflection.

A very important aspect of the effectiveness of the NSM technique, regarding the analyzed beams, is the capacity of this technique to mobilize the yield stress of the stirrups before the maximum load of the strengthened beams has been attained.

\section{ACKNOWLEDGEMENTS}

The authors wish to acknowledge the support provided by the "Empreiteiros Casais", Degussa, S\&P® and Secil (Unibetão, Braga). The study reported in this paper forms a part of the research program supported by FCT, PTDC/ECM/105700/2008.

\section{REFERENCES}

[1] ACI Committee 440, "Guide for the design and construction of externally bonded FRP systems for strengthening concrete structures”, American Concrete Institute, 118 pp. (2002).

[2] fib - Bulletin 14, "Externally bonded FRP reinforcement for RC structures”, Technical report by Task Group 9.3 FRP (Fiber Reinforced Polymer) reinforcement for concrete structures, Féderation Internationale du Béton 
- fib, July, 130 pp. (2001).

[3] Bakis, C.E., Bank, L.C., Brown, V.L., Cosenza, E., Davalos, J.F., Lesko, J.J., Machida, A., Riskalla, S.H. and Triantafillou, T.C., "Fiber-reinforced polymer composites for construction - state-of-the-art review”, Journal of Composites for Construction, 6(2), 73-87 (2002).

[4] Taerwe, L., Khalil, H. and Matthys, S., "Behaviour of RC beams strengthened in shear by external CFRP sheets”, Proceedings of the Third International Symposium Non-Metallic (FRP) Reinforcement for Concrete Structures (FRPRCS-3), JCI, Japan, pp. 483-490 (1997).

[5] Khalifa, A. and Nanni, A., "Improving shear capacity of existing RC T-section beams using CFRP composites", Journal Cement \& Concrete Composites, 22(2), 165-174 (2000).

[6] Chaallal, O., Nollet, M.J. and Perraton D., "Shear strengthening of RC beams by externally bonded side CFRP Strips”, Journal of Composites for Construction, 2(2), 111-113 (1998).

[7] Basler, M., White, D. and Desroches, M., "Shear strengthening with bonded CFRP L-shaped plates", Field Applications of FRP Reinforcement: Case Studies, ACI International SP-215, Editors: Sami Rizkalla and Antonio Nanni, pp. 373-384 (2003).

[8] De Lorenzis, L. and Nanni, A., "Shear strengthening of reinforced concrete beams with Near-surface mounted fiber-reinforced polymer rods", ACI Structural Journal, 98(1), 60-68 (2001).

[9] Barros, J.A.O. and Dias, S.J.E., "Shear strengthening of reinforced concrete beams with laminate strips of CFRP”, Proceedings of the International Conference Composites in Constructions - CCC2003, Cosenza, Italy, 16-19 September, 289-294 (2003).

[10] Nanni, A., Di Ludovico, M. and Parretti, R., "Shear strengthening of a PC bridge girder with NSM CFRP rectangular bars", Advances in Structural Engineering, 7(4), 97-109 (2004).

[11] El-Hacha, R. and Riskalla, S.H., "Near-surface-mounted fiber-reinforced polymer reinforcements for flexural strengthening of concrete structures”, ACI Structural Journal, 101(5), 717-726 (2004).

[12] Costa, I.G. and Barros, J.A.O., "Assessment of the bond behavior of NSM FRP materials by pullout tests", First Middle East Conference on Smart Monitoring, Assessment and Rehabilitation of Civil Structures, Dubai, 8-10 February (2011).

[13] Barros, J.A.O. and Dias, S.J.E., “Near surface mounted CFRP laminates for shear strengthening of concrete beams", Journal Cement and Concrete Composites, 28(3), 276-292 (2006).

[14] Dias, S.J.E. and Barros, J.A.O., "Performance of reinforced concrete T beams strengthened in shear with NSM CFRP laminates", Engineering Structures Journal, Volume 32, Issue 2, February, pp. 373-384 (2010). 
[15] Dias, S.J.E. and Barros, J.A.O., "Influence of the concrete properties in the effectiveness of the NSM CFRP laminates for the shear strengthening of RC beams", Proceedings of the 5th International Conference on FRP Composites in Civil Engineering - CICE2010, Beijing, China, 27-29 September (2010).

[16] Sena-Cruz, J.M. and Barros, J.A.O., "Bond between near-surface mounted CFRP laminate strips and concrete in structural strengthening”, Journal of Composites for Construction, 8(6), 519-527 (2004).

[17] EN 206-1, “Concrete - Part 1: Specification, performance, production and conformity.” European standard, CEN, 69 pp. (2000).

[18] EN 10002-1, “Metallic materials - Tensile testing. Part 1: Method of test (at ambient temperature)”, European Standard, CEN, Brussels, Belgium, 35 pp. (1990).

[19] ISO 527-5, “Plastics - Determination of tensile properties - Part 5: Test conditions for unidirectional fibrereinforced plastic composites”, International Organization for Standardization (ISO), Geneva, Switzerland, 9 pp. (1997).

[20] Degussa Construction Chemicals Portugal, Technical Report MBrace Resin 220, May (2003).

[21] Bonaldo, E., Barros, J.A.O. and Lourenço, P.J.B., “Steel fibre reinforced concrete and CFRP laminate strips for high effective flexural strengthening of RC slabs“, Technical report 05-DEC/E-14, Dep. Civil Eng., School Eng. University of Minho, 103 pp., October (2005).

[22] Bianco, V., Barros, J.A.O., Monti, G., "New approach for modeling the contribution of NSM FRP strips for shear strengthening of RC beams”, ASCE Journal Composites for Construction, 14(1), 36-48, January/February (2010).

[23] prEN 1992-1-1, "Eurocode 2: Design of concrete structures - Part 1: General rules and rules for buildings", April 2002.

\section{TABLES AND FIGURES}

\section{List of Tables:}

Table 1 - CFRP shear strengthening configurations of the tested beams

Table 2 - Average values of the properties of intervening materials

Table 3 - Position of the strain gauges in the pre-cracked NSM shear strengthened beams

Table 4 - Results for the beams tested without pre-cracks

Table 5 - Results of the ultimate bearing capacity: effect of pre-cracking induced in concrete 


\section{List of Figures:}

Fig. 1 - Geometry of the type of beam, steel reinforcements common to all beams, support and load conditions (dimensions in $\mathrm{mm})$

Fig. 2 - Details of the reference beams (dimensions in $\mathrm{mm}$ )

Fig. 3 - Localization of the steel stirrups (continuous line) and CFRP laminates (dashed line) in the CFRP shear strengthened beams (dimensions in $\mathrm{mm}$ )

Fig. 4 - Positions of the strain gauges in the monitored: a) CFRP A and CFRP C; b) CFRP B; c) stirrups

Fig. 5 - Force $v s$ deflection at the loaded-section (pre-cracking test)

Fig. 6 - Pre-cracked beams (Top line of photos: after the pre-cracking test; Bottom line of photos: after the NSM shear strengthening execution)

Fig. 7 - Beams with $\rho_{s w}=0.10 \%$ : Force $v s$ deflection at the loaded-section for the beams with the lower (a) and higher (b) percentage of CFRP shear strengthening and $\Delta F / F^{3 S-R} v s$ deflection at the loaded-section for the beams with the lower (c) and higher (d) percentage of CFRP shear strengthening

Fig. 8 - Beams with $\rho_{s w}=0.16 \%$ : Force $v s$ deflection at the loaded-section for the beams with the lower (a) and higher (b) percentage of CFRP shear strengthening and $\Delta F / F^{5 S-R} v s$ deflection at the loaded-section for the beams with the lower (c) and higher (d) percentage of CFRP shear strengthening

Fig. 9 - Influence of the percentage of existing steel stirrups in the effectiveness of the NSM shear strengthening technique using CFRP laminates

Fig. 10 - Details of the failure zones of the tested beams

Fig. 11 - Details of the failure modes of the NSM beams

Fig. 12 - Strains in the monitored laminates and steel stirrup in the 3S-5LI60 beam

Fig. 13 - Pre-cracking effect in terms of the force $v s$ deflection at the loaded-section: a) beams with $\rho_{s w}=0.10 \%$, b) beams with $\rho_{s w}=0.16 \%$

Fig. 14 - Details of the failure zones of the pre-cracked NSM shear strengthened beams

Fig. 15 - Strains in the monitored laminates and steel stirrup in the 5S-5LI60F beam 
Table 1 - CFRP shear strengthening configurations of the tested beams

\begin{tabular}{|c|c|c|c|c|c|c|}
\hline \multicolumn{2}{|c|}{ Beams } & \multirow{2}{*}{ Pre-cracking } & \multirow{2}{*}{ Laminates } & \multirow{2}{*}{$\underset{\left({ }^{\circ}\right)}{\text { CFRP angle }}\left[\theta_{f}\right]$} & \multirow{2}{*}{$\begin{array}{c}\text { CFRP spacing }\left[s_{f}\right] \\
(\mathrm{mm})\end{array}$} & \multirow{2}{*}{$\begin{array}{c}\text { CFRP percentage }\left[\rho_{f}\right] \\
(\%)^{\mathrm{d}}\end{array}$} \\
\hline$\rho_{s w}=0.10 \%^{\mathrm{a}}$ & $\rho_{s w}=0.16 \%^{\mathrm{b}}$ & & & & & \\
\hline $3 \mathrm{~S}-6 \mathrm{LV}$ & - & \multirow{2}{*}{ No } & $2 \times 6$ & \multirow{2}{*}{90} & 180 & 0.08 \\
\hline 3S-10LV & - & & $2 \times 10$ & & 114 & 0.13 \\
\hline 3S-5LI45 & 5S-5LI45 & No & \multirow{3}{*}{$2 \times 5$} & \multirow{4}{*}{45} & & \\
\hline 3S-5LI45F1 & 5S-5LI45F & \multirow{2}{*}{ Yes } & & & 275 & 0.08 \\
\hline 3S-5LI45F2 & - & & & & & \\
\hline 3S-9LI45 & 5S-9LI45 & No & $2 \times 9$ & & 157 & 0.13 \\
\hline 3S-5LI60 & 5S-5LI60 & No & \multirow{2}{*}{$2 \times 5$} & \multirow{3}{*}{60} & \multirow{2}{*}{243} & \multirow{2}{*}{0.07} \\
\hline- & 5S-5LI60F & Yes & & & & \\
\hline 3S-8LI60 & 5S-8LI60 & No & $2 \times 8$ & & 162 & 0.11 \\
\hline
\end{tabular}

a $3 \mathrm{~S}-\mathrm{R}$ is the reference beam without CFRP (Fig. 2); ${ }^{\mathrm{b}} 5 \mathrm{~S}-\mathrm{R}$ is the reference beam without CFRP (Fig. 2); ${ }^{\mathrm{c}}$ Angle between the CFRP fiber direction and the beam axis; ${ }^{\mathrm{d}}$ The CFRP percentage was obtained from $\rho_{f}=\left(2 a_{f} b_{f}\right) /\left(b_{w} s_{f} \sin \theta_{f}\right)$ where $a_{f}=1.4 \mathrm{~mm}$ and $b_{f}=9.5 \mathrm{~mm}$ are the dimensions of the laminate cross section, and $b_{w}=180 \mathrm{~mm}$ is the beam web width.

Table 2 - Average values of the properties of intervening materials

\begin{tabular}{|c|c|c|c|c|c|c|c|}
\hline \multirow[b]{2}{*}{ Concrete } & \multicolumn{7}{|c|}{ Compressive strength } \\
\hline & \multicolumn{7}{|c|}{$\begin{array}{c}f_{c m}=59.4 \mathrm{MPa} \\
\text { (at } 97 \text { days - age of beam tests) }\end{array}$} \\
\hline \multirow{3}{*}{ Steel } & Tensile strength & $\phi 6$ & $\phi 8$ & $\phi 12$ & $\begin{array}{c}\phi 16 \\
\text { (Type 1) }\end{array}$ & $\begin{array}{c}\phi 16 \\
\text { (Type 2) }\end{array}$ & $\phi 32$ \\
\hline & Yield stress $\left[f_{\text {sym }}\right](\mathrm{MPa})$ & 551 & 470 & 450 & 434 & 544 & 716 \\
\hline & Maximum stress $\left[f_{\text {sum }}\right](\mathrm{MPa})$ & 602 & 611 & 579 & 572 & 658 & 908 \\
\hline \multirow{2}{*}{$\begin{array}{c}\text { CFRP } \\
\text { Laminate }\end{array}$} & \multicolumn{2}{|l|}{ Maximum tensile strength } & \multicolumn{3}{|c|}{ Young's Modulus } & \multicolumn{2}{|c|}{ Maximum strain } \\
\hline & \multicolumn{2}{|l|}{$f_{\text {fum }}=2847.9 \mathrm{MPa}$} & \multicolumn{3}{|c|}{$E_{f m}=174.3 \mathrm{GPa}$} & \multicolumn{2}{|c|}{$\varepsilon_{f u}=1.63 \%$} \\
\hline
\end{tabular}


Table 3 - Position of the strain gauges in the pre-cracked NSM shear strengthened beams

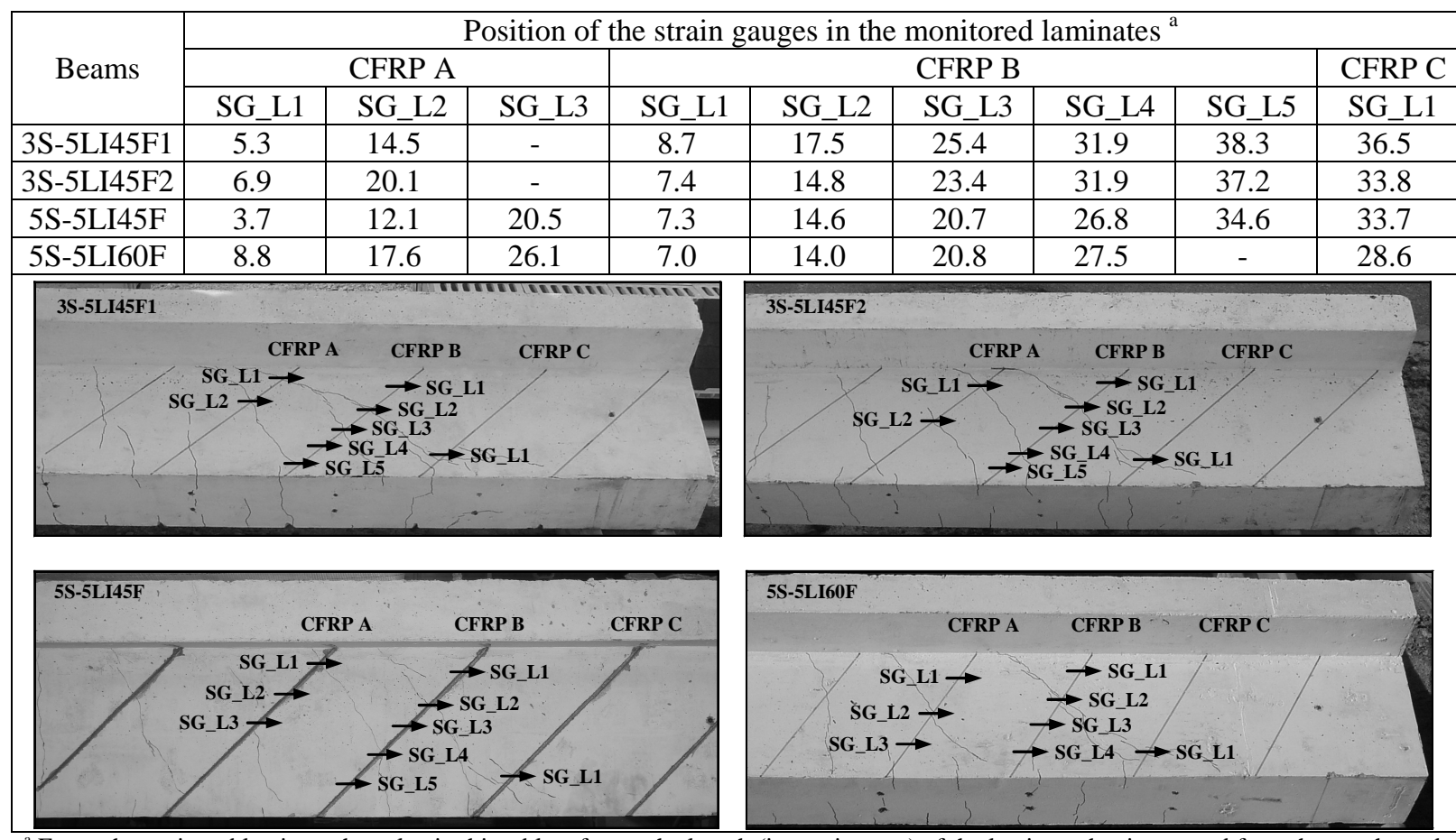

${ }^{\mathrm{a}}$ For each monitored laminate the value in this table refers to the length (in centimeters) of the laminate that is counted from the top the web beam to the position of the SG.

Table 4 - Results for the beams tested without pre-cracks

\begin{tabular}{|c|c|c|c|c|c|}
\hline Beams & $\begin{array}{l}F_{\text {max }} \\
(\mathrm{kN})\end{array}$ & $\begin{array}{c}\Delta F_{\max } / F_{\max }^{r e f} \\
(\%)\end{array}$ & $\begin{array}{l}u_{F_{\max }} \\
(\mathrm{mm})\end{array}$ & $\begin{array}{c}\varepsilon_{C F R P}^{\max } \\
(\%)\end{array}$ & 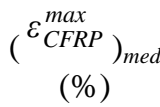 \\
\hline C-R & 255.8 & - & 2.98 & - & - \\
\hline 3S-R & 359.9 & - & 5.86 & - & - \\
\hline $3 \mathrm{~S}-6 \mathrm{LV}$ & 387.0 & 7.5 & 5.78 & 0.82 & 0.39 \\
\hline $3 \mathrm{~S}-10 \mathrm{LV}$ & 491.7 & 36.6 & 8.32 & 0.85 & 0.68 \\
\hline 3S-5LI45 & 492.1 & 36.7 & 8.54 & 1.20 & 0.84 \\
\hline 3S-9LI45 & 563.6 & 56.6 & 11.40 & 1.04 & 0.95 \\
\hline 3S-5LI60 & 497.9 & 38.3 & 8.83 & 1.50 & 0.96 \\
\hline 3S-8LI60 & 584.5 & 62.4 & 12.69 & 0.90 & 0.73 \\
\hline $5 \mathrm{~S}-\mathrm{R}$ & 409.7 & - & 6.86 & - & - \\
\hline 5S-5LI45 & 559.5 & 36.6 & 11.09 & 1.28 & 0.99 \\
\hline 5S-9LI45 & 627.5 & 53.2 & 11.18 & 0.84 & 0.75 \\
\hline 5S-5LI60 & 556.4 & 35.8 & 9.98 & 1.41 & 0.91 \\
\hline 5S-8LI60 & 654.6 & 59.8 & 12.47 & 0.88 & 0.82 \\
\hline
\end{tabular}


Table 5 - Results of the ultimate bearing capacity: effect of pre-cracking induced in concrete

\begin{tabular}{|c|c|c|c|c|c|}
\hline Beams & $\begin{array}{c}F_{\text {max }} \\
(\mathrm{kN})\end{array}$ & $\begin{array}{c}\Delta F_{\max } / F_{\max }^{\text {ref }} \\
(\%)\end{array}$ & $\begin{array}{c}u_{F_{\max }} \\
(\mathrm{mm})\end{array}$ & $\begin{array}{c}\varepsilon_{C F R P}^{\max } \\
(\%)\end{array}$ & $\begin{array}{c}\varepsilon_{C F R P}^{\max } \\
(\%)\end{array}$ \\
\hline 3S-R & 359.9 & - & 5.86 & - & - \\
\hline 3S-5LI45 & 492.1 & 36.7 & 8.54 & 1.20 & 0.84 \\
\hline 3S-5LI45F1 & 531.4 & 47.7 & 9.00 & 1.49 & 1.20 \\
\hline 3S-5LI45F2 & 490.6 & 36.3 & 8.36 & 1.35 & - \\
\hline 5S-R & 409.7 & - & 6.86 & 1.06 \\
\hline 5S-5LI45 & 559.5 & 36.6 & 11.09 & 1.28 & 0.99 \\
\hline 5S-5LI45F & 611.9 & 49.4 & 12.18 & 1.21 & 1.03 \\
\hline 5S-5LI60 & 556.4 & 35.8 & 9.98 & 1.41 & 0.91 \\
\hline 5S-5LI60F & 554.8 & 35.4 & 9.73 & 1.48 & 1.10 \\
\hline
\end{tabular}



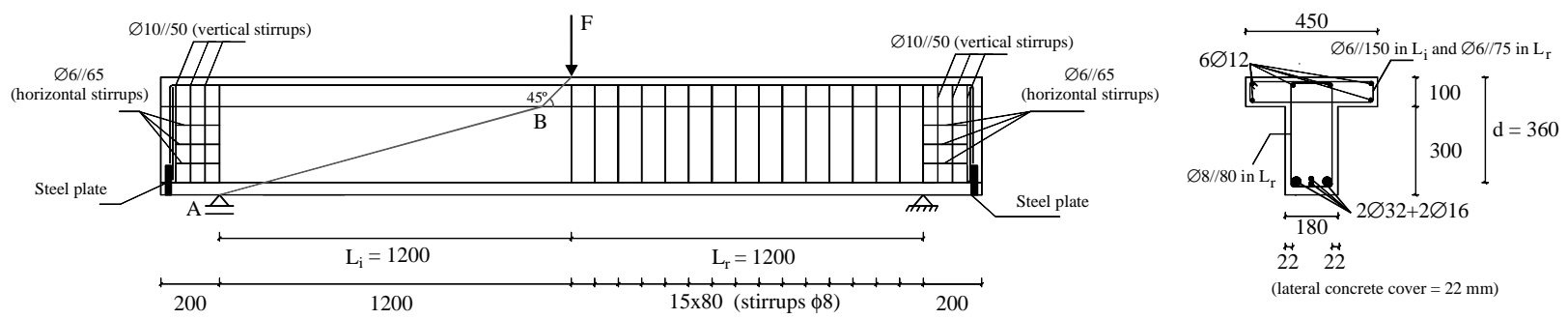

Fig. 1 - Geometry of the type of beam, steel reinforcements common to all beams, support and load conditions (dimensions in $\mathrm{mm}$ )

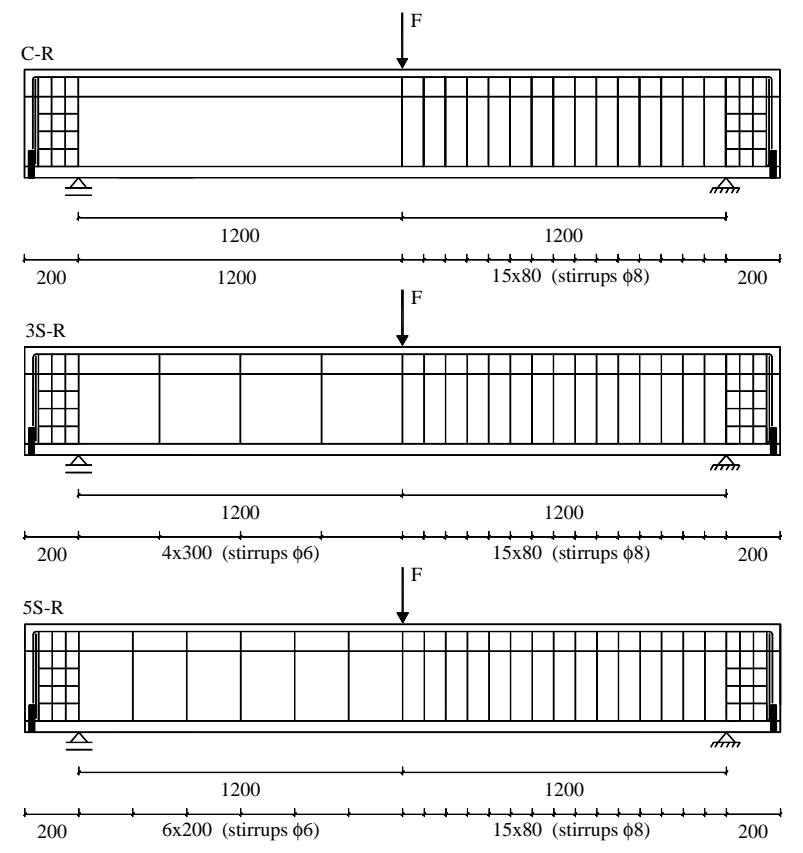

Fig. 2 - Details of the reference beams (dimensions in $\mathrm{mm}$ ) 

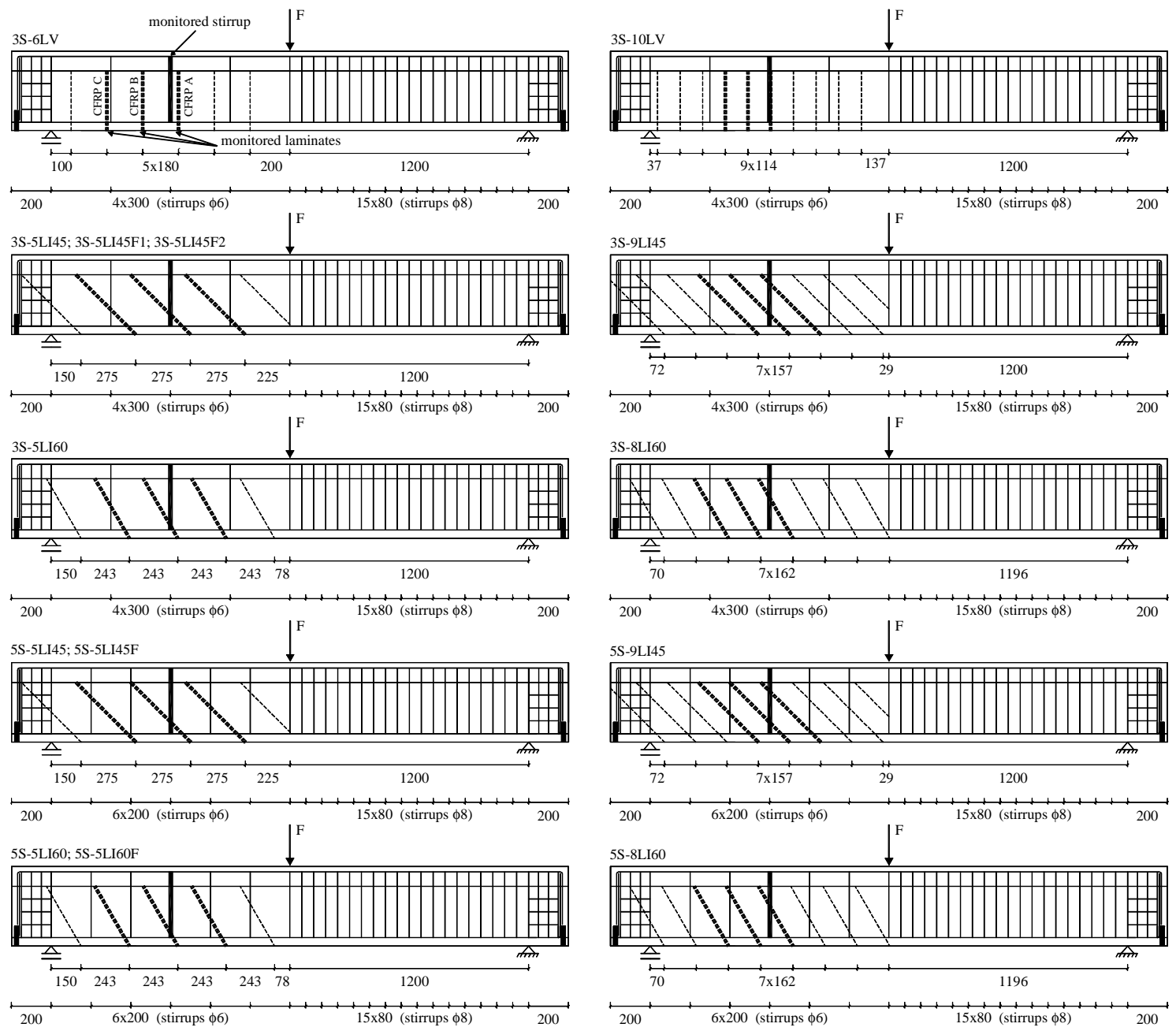

Legend (see exemple in 3S-6LV beam): | monitored stirrup

Monitored laminates (CFRP A: nearest the loaded section; CFRP B between the CFRP A and CFRP C)

Fig. 3 - Localization of the steel stirrups (continuous line) and CFRP laminates (dashed line) in the CFRP shear strengthened beams (dimensions in $\mathrm{mm}$ ) 


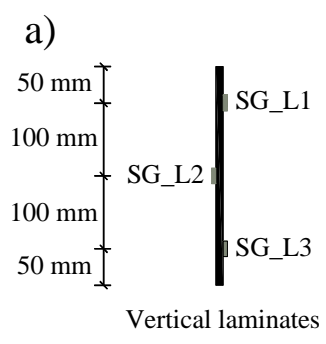

b)

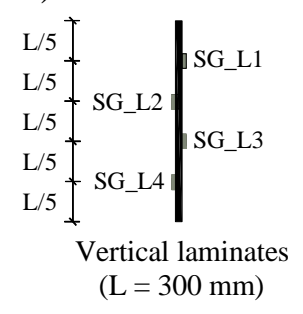

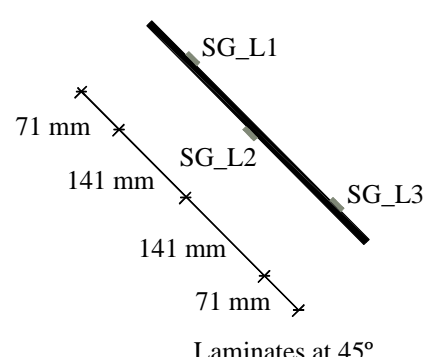

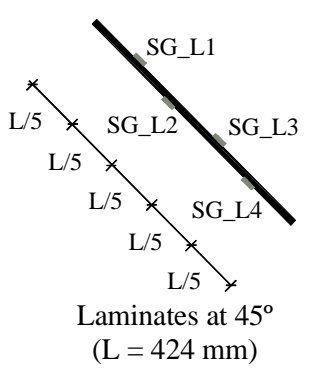

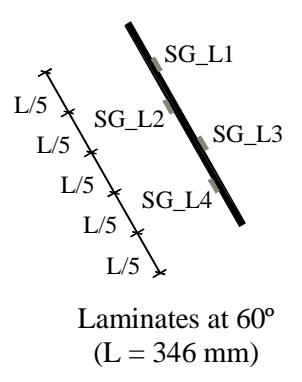

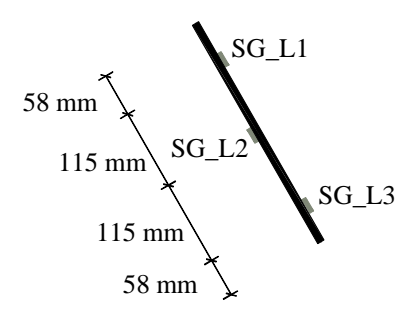

Laminates at $60^{\circ}$

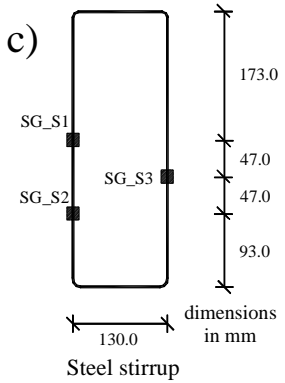

Fig. 4 - Positions of the strain gauges in the monitored: a) CFRP A and CFRP C; b) CFRP B; c) stirrups

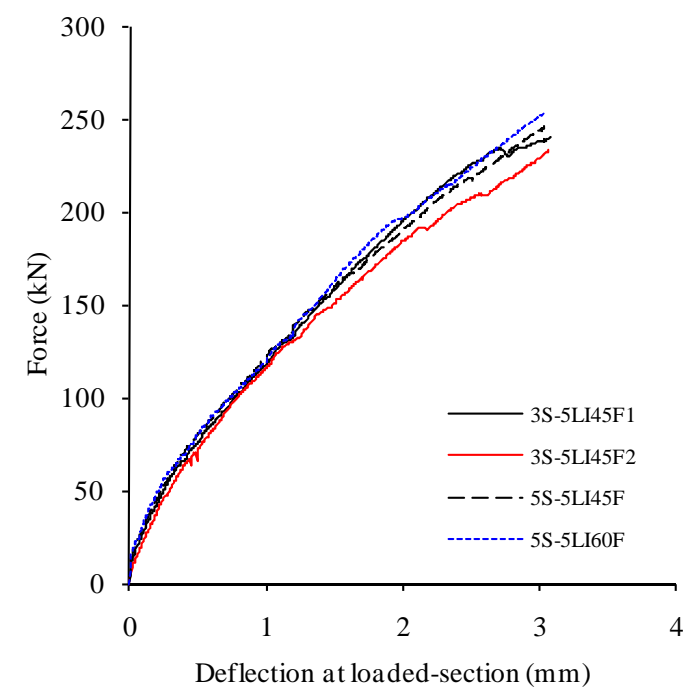

Fig. 5 - Force $v s$ deflection at the loaded-section (pre-cracking test)
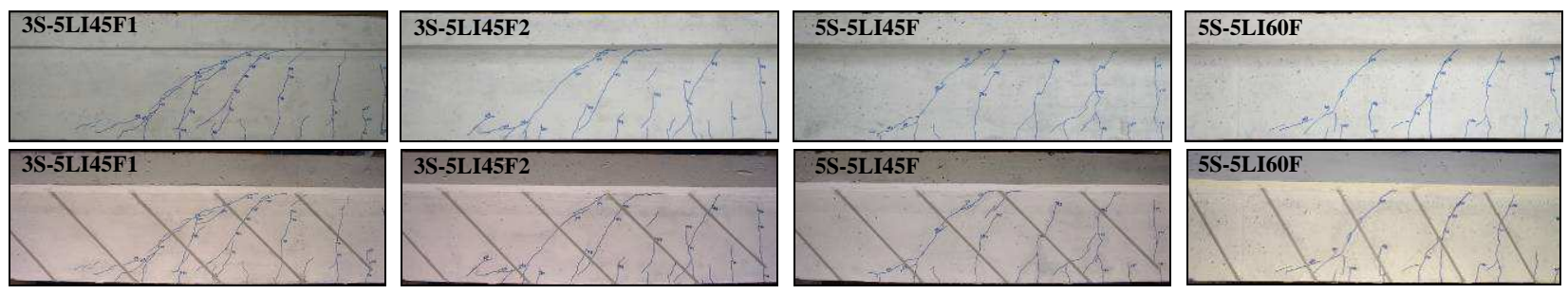

Fig. 6 - Pre-cracked beams (Top line of photos: after the pre-cracking test; Bottom line of photos: after the NSM shear strengthening execution) 

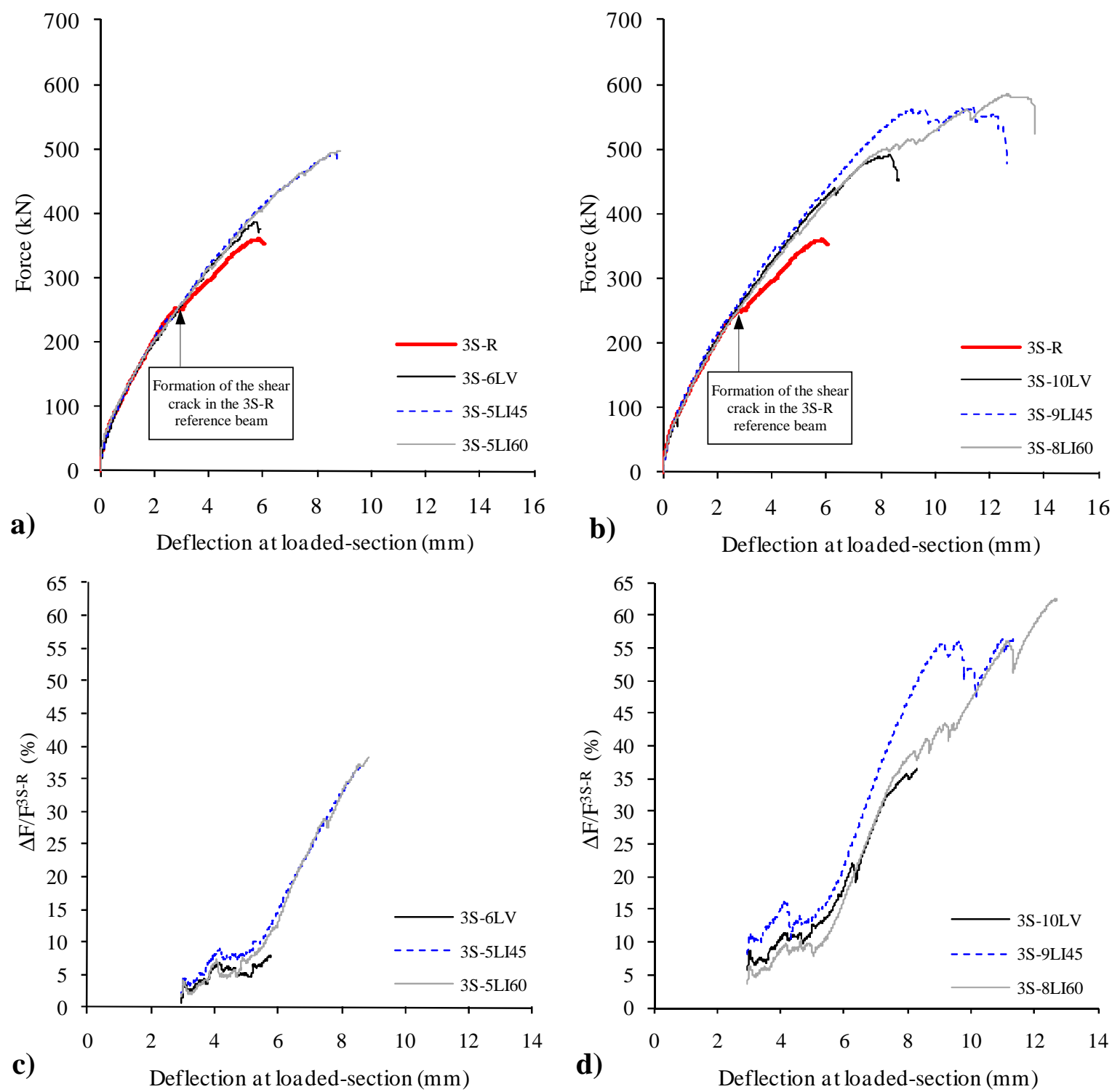

Fig. 7 - Beams with $\rho_{s w}=0.10 \%$ : Force $v s$ deflection at the loaded-section for the beams with the lower (a) and higher (b) percentage of CFRP shear strengthening and $\Delta F / F^{3 S-R} v s$ deflection at the loaded-section for the beams with the lower (c) and higher (d) percentage of CFRP shear strengthening 

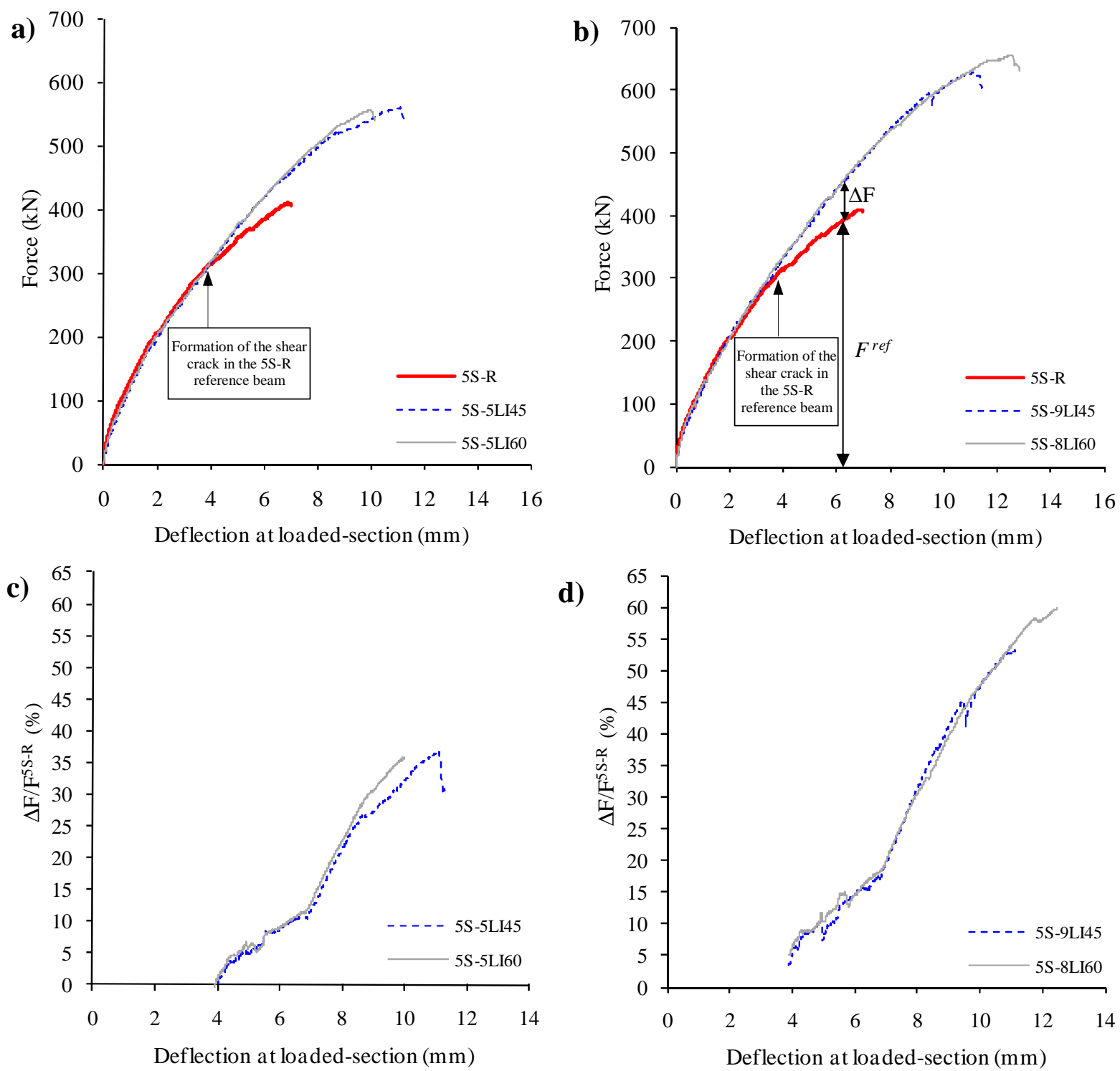

Fig. 8 - Beams with $\rho_{s w}=0.16 \%$ : Force $v s$ deflection at the loaded-section for the beams with the lower a) and higher b) percentage of CFRP shear strengthening and $\Delta F / F^{S S-R} v s$ deflection at the loaded-section for the beams with the lower c) and higher (d) percentage of CFRP shear strengthening 


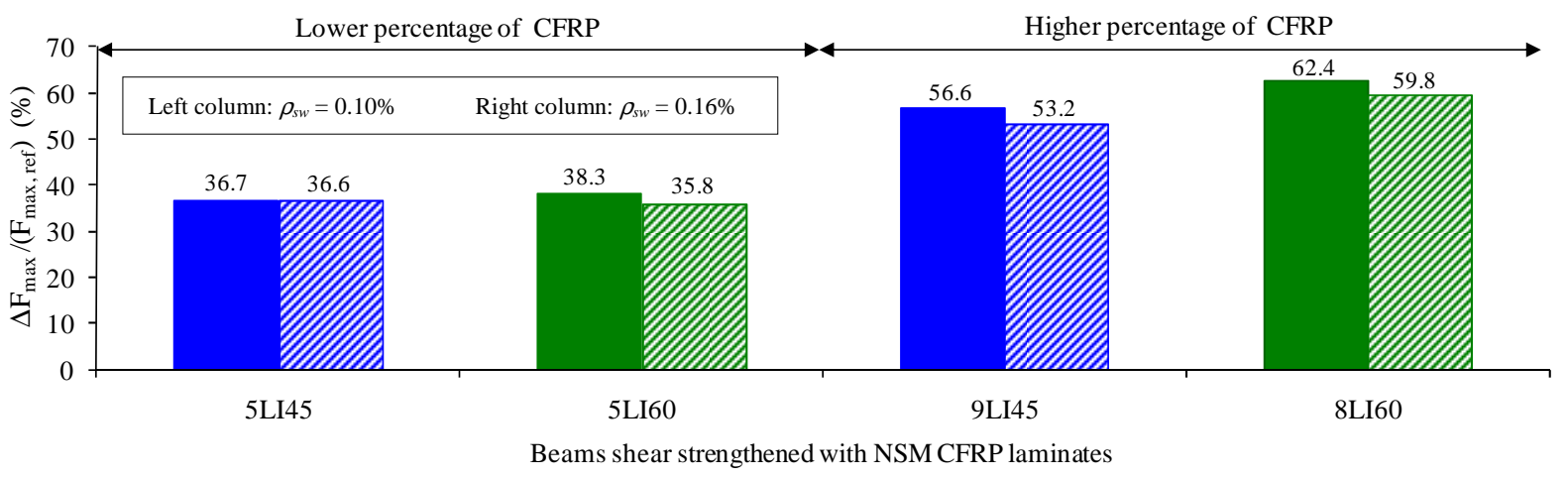

Fig. 9 - Influence of the percentage of existing steel stirrups in the effectiveness of the NSM shear strengthening technique using CFRP laminates
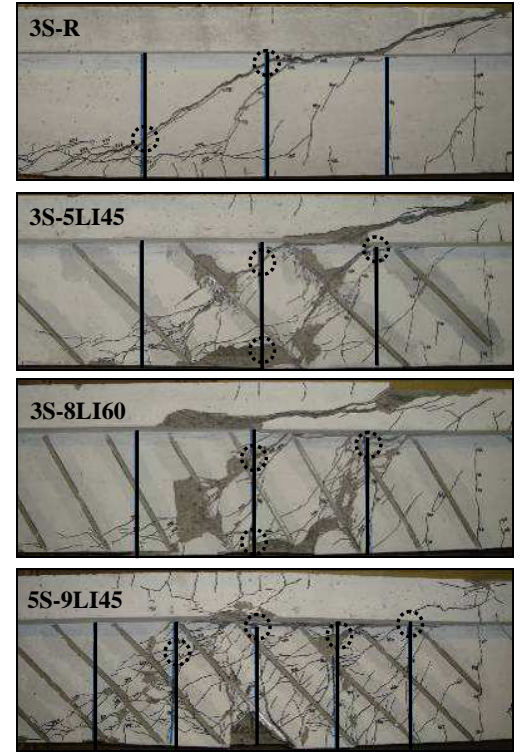
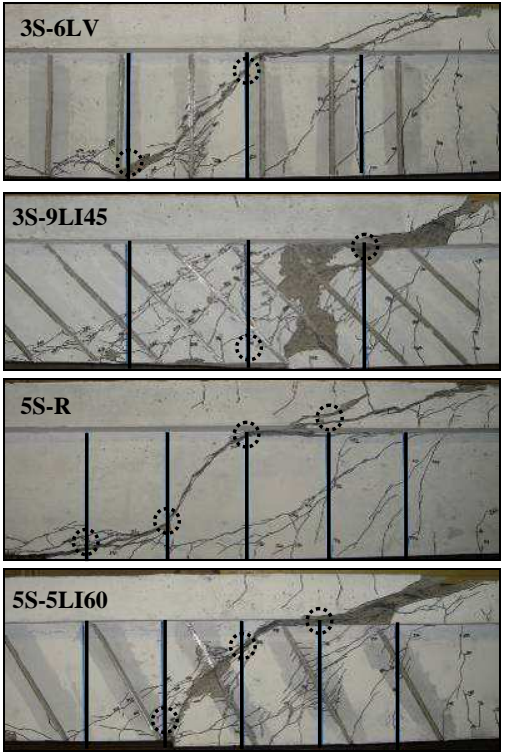
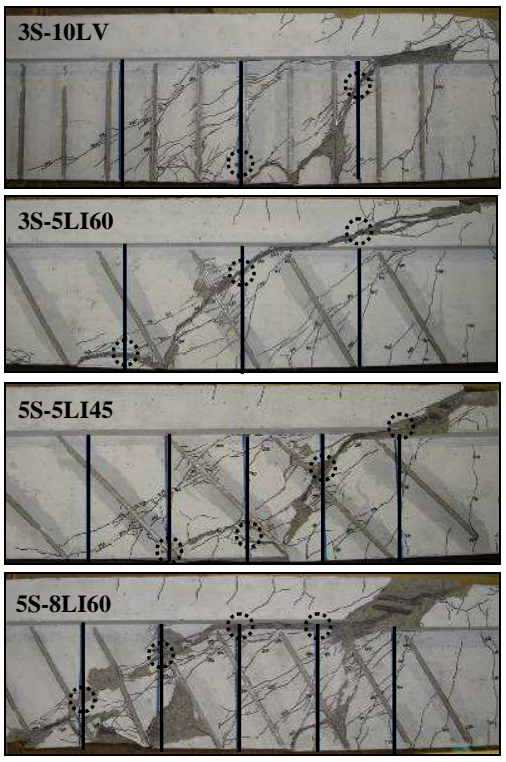

Fig. 10 - Details of the failure zones of the tested beams 


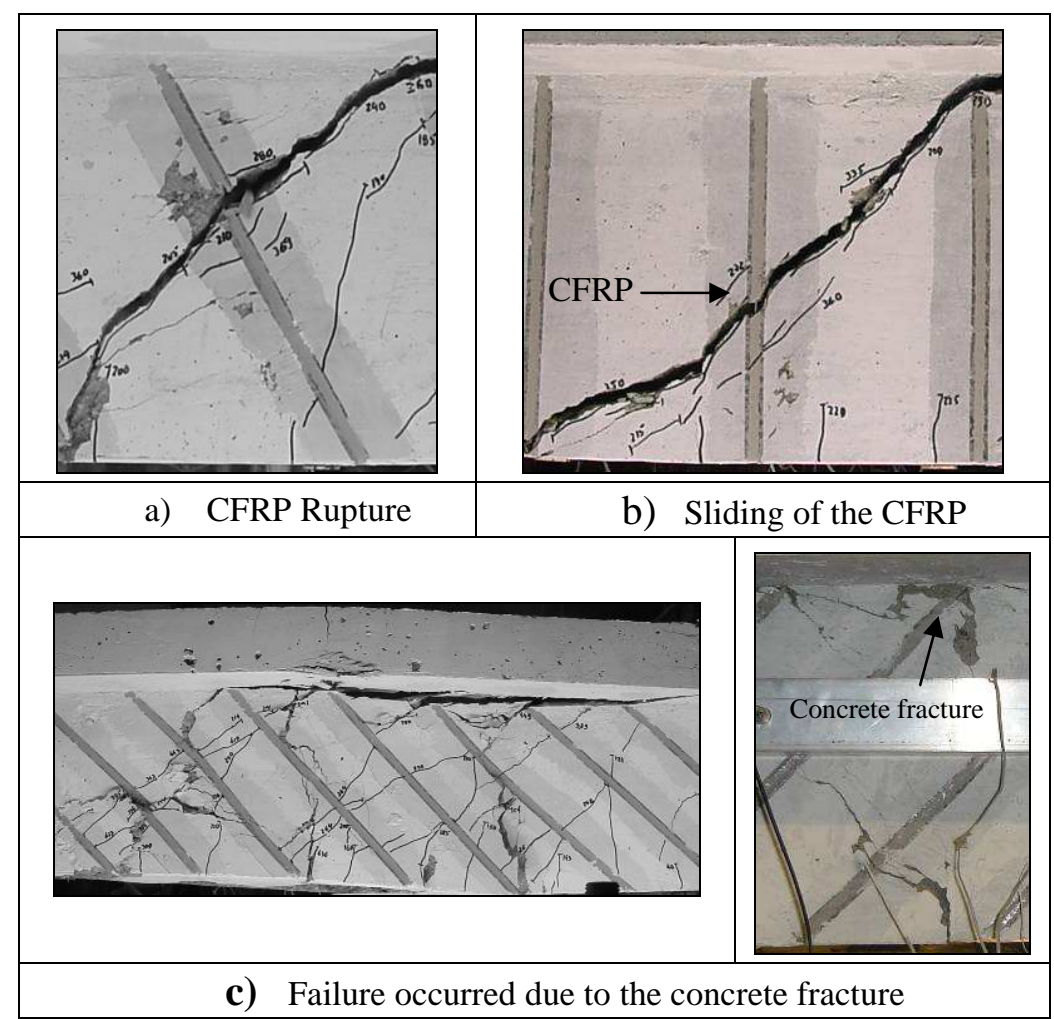

Fig. 11 - Details of the failure modes of the NSM beams 


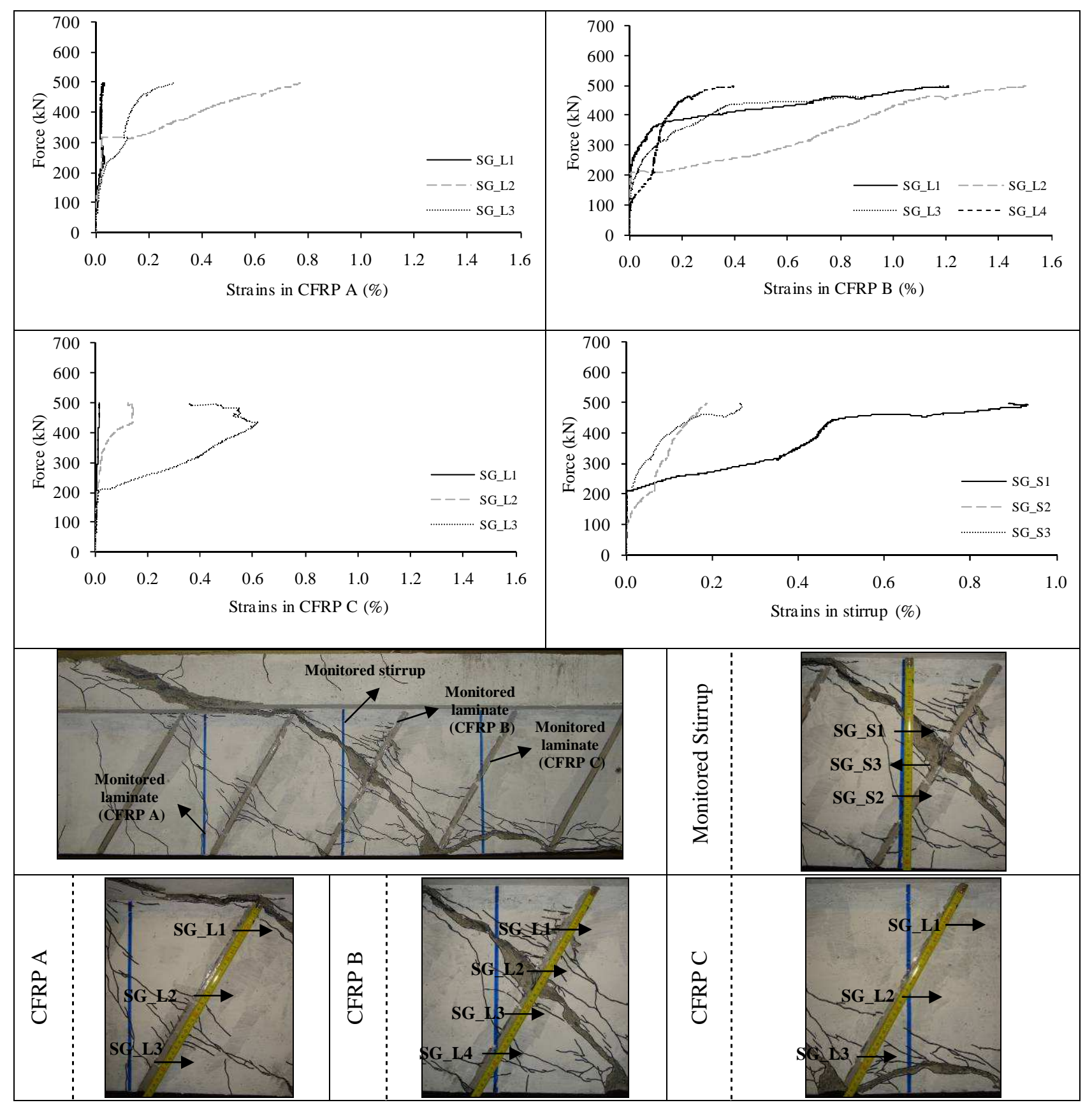

Fig. 12 - Strains in the monitored laminates and steel stirrup in the 3S-5LI60 beam 

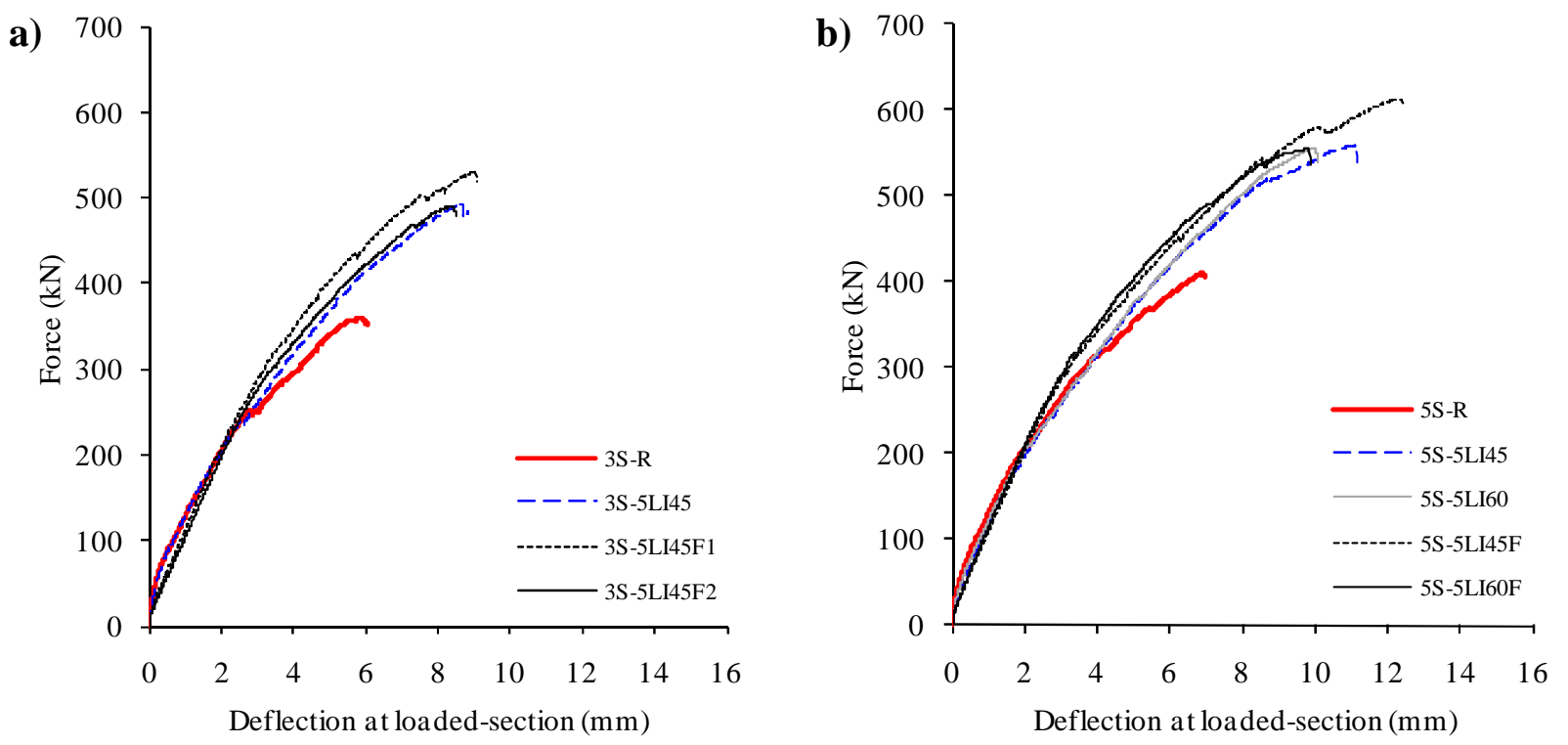

Fig. 13 - Pre-cracking effect in terms of the force $v s$ deflection at the loaded-section: a) beams with $\rho_{s w}=0.10 \%$, b) beams with $\rho_{s w}=0.16 \%$
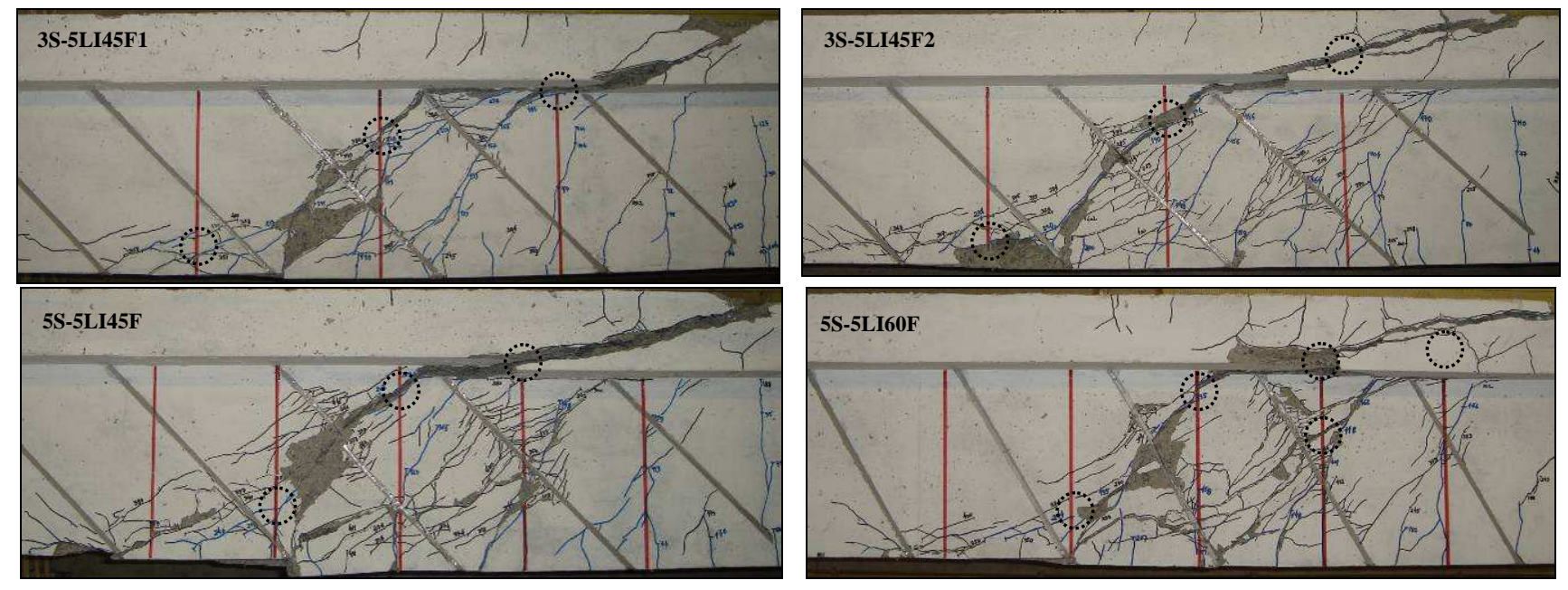

Fig. 14 - Details of the failure zones of the pre-cracked NSM shear strengthened beams 

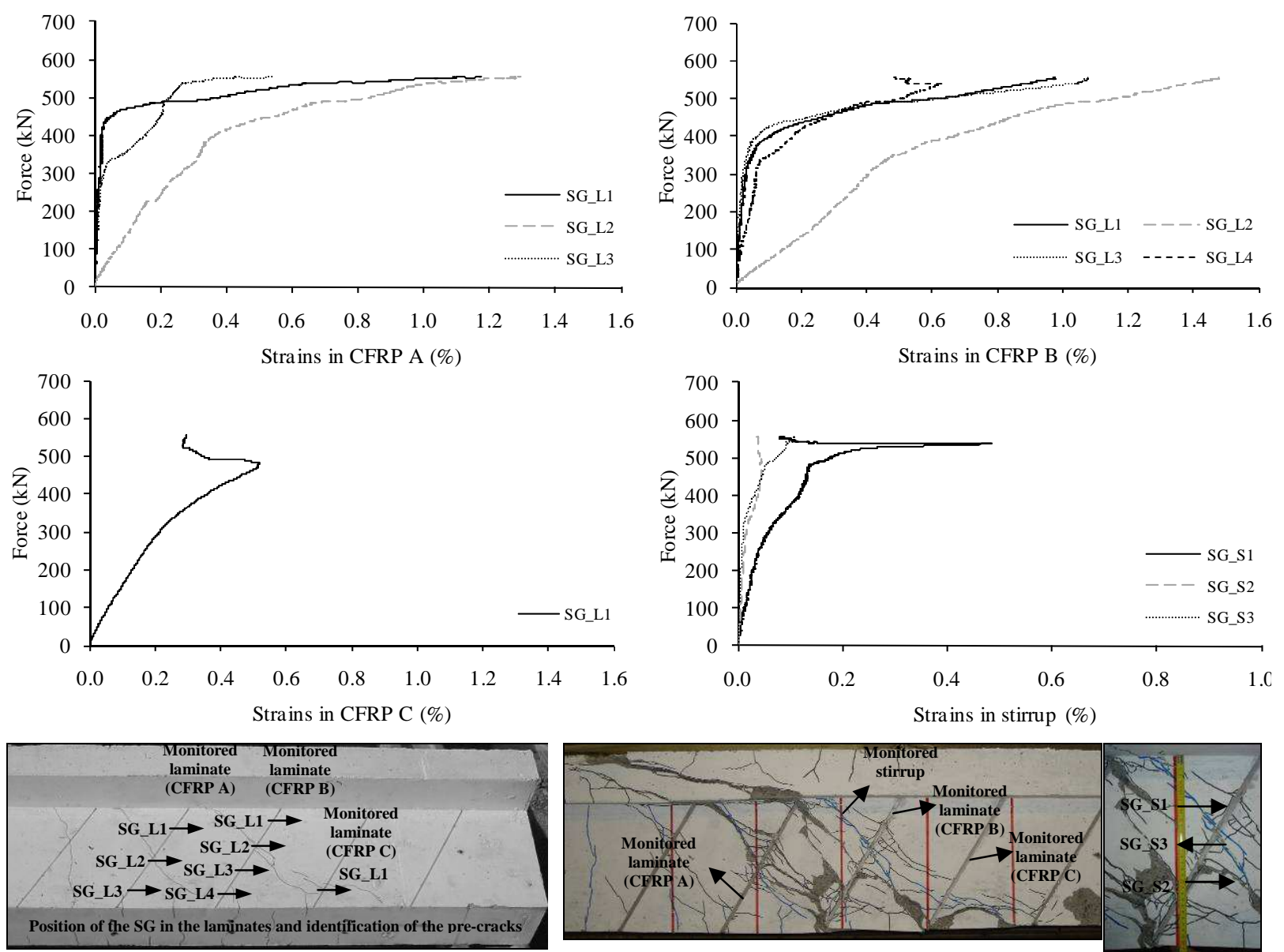

Fig. 15 - Strains in the monitored laminates and steel stirrup in the 5S-5LI60F beam 